\title{
HIGHLIGHT
}

\section{Does defective hypoxia signalling cause type 2 diabetes?}

Jörg Dötsch, Ina Knerr, Wolfgang Rascher and Udo Meißner

Department of Pediatrics, Friedrich-Alexander-University Erlangen-Nuremberg, Loschgestrasse 15, 91054 Erlangen, Germany

(Correspondence should be addressed to Jörg Dötsch; Email: Joerg.Doetsch@kinder.imed.uni-erlangen.de)

Presently more than 200 Million people are suffering from type 2 diabetes (1). Considerable progress has been achieved in the understanding of the pathogenetic role of insulin resistance $(2,3)$. However, less is known with regard to a dysregulation of islet cell function. Three pathogenetic mechanisms have been identified. They include alterations in glucose sensing, insulin secretion, and insulin signalling (Fig. 1). Genetic alterations of insulin secretion are found in patients with Maturity Onset Diabetes of the Young (MODY). Five out of six mutations leading to MODY involve transcription factors that regulate insulin signalling (4).

However, several questions in the pathogenetic field of type 2 diabetes remain unsolved.

1. Are genes other than those causing MODY involved in the pathogenesis of type 2 diabetes?

2. Is there a key player, regulating various genes involved in insulin secretion, insulin signalling and glucose sensing?

3. Does the deeper understanding of the pathogenesis of type 2 diabetes provide new targets of the treatment of the disease?

To examine this issue Gunton and co-workers (5) compared the gene expression profile of pancreatic islets from patients with type 2 diabetes and non-affected controls using oligonucleotide microarrays and realtime PCR. Apart from expected changes in genes known to be involved in the pathogenesis of type 2 diabetes mellitus, there was a marked downregulation of the gene for hypoxia-inducible factor-1 $\beta$ (HIF-1 $\beta$ ) also called aryl hydrocarbon receptor nuclear translocator (ARNT). The microarray data were confirmed by realtime PCR.

Experimental downregulation of ARNT in the insulin-secreting insulinoma cell line Min6 using siRNA resulted in a marked reduction of genes involved in glucose-stimulated insulin secretion such as
Hepatocyte Nuclear Factors (HNF) $4 \alpha$ and $1 \alpha$. Moreover, genes involved in glucose metabolism and insulin secretion were significantly decreased as a consequence of ARNT suppression.

To examine the role of ARNT in vivo, Gunton and co-workers created a mouse with a targeted deletion of pancreatic ARNT ( $\beta$-ARNT) (5). Female $\beta$-ARNT mice had an abolished glucose-stimulated insulin release, whereas male animals had a milder phenotype showing slightly higher serum glucose concentrations but a normal in vivo insulin secretion in response to glucose. However, in isolated islets the secretion of insulin was attenuated when glucose concentrations of $8.3 \mathrm{mM}$ and above were applied. However, total $\beta$-cell mass and total insulin concentration was not changed and insulin secretion was unaltered in response to lower concentrations of glucose. One of the MODY genes, $\mathrm{HNF} 4 \alpha$, was significantly decreased by more than $90 \%$ in the islets of the $\beta$-ARNT knock out mice. As in the cellular ARNT knock out, a number of genes involved in glucose metabolism, insulin secretion, and insulin receptor were significantly decreased.

Finally, by showing that ARNT is not reduced in the diabetic $\mathrm{db} / \mathrm{db}$ and $\mathrm{ob} / \mathrm{ob}$ mice, Gunton and co-workers prove that the downregulation of the gene is not nonspecifically caused by diabetes, hyperglycaemia, or insulin resistance (5).

ARNT does not appear to be merely a factor that is epigenetically regulated and appears to play an important role in the genesis of type 2 diabetes. Whether ARNT itself or more essential factors further upstream in the cascade are the essential key player, remains to be shown. Would an early correction of ARNT suppression delay the onset of type 2 diabetes? Furthermore, do the results of Gunton and co-workers suggest an involvement of hypoxia induced processes in the genesis of type 2 diabetes? These issues may mark questions appearing worth to be investigated in further research projects. 


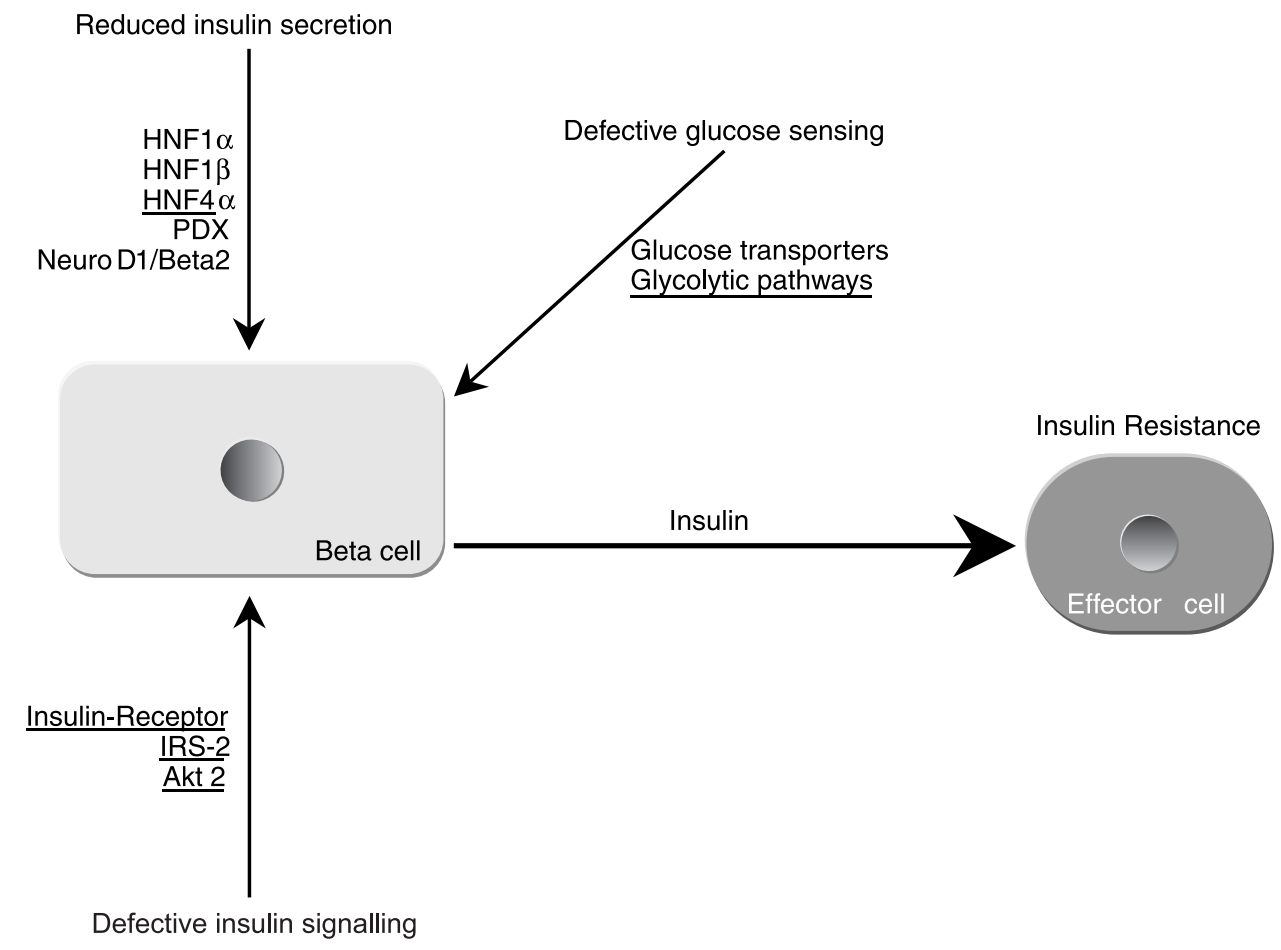

Figure 1 Pathogenic mechanisms involved in the genesis of type 2 diabetes mellitus. ARNT/ HIF-1 $\beta$ downregulation leads to a reduction of the genes that are underlined.

In summary, the exciting work by Gunton and coworkers suggests at least a yet unnoticed essential player in the cascade of type 2 diabetes genesis, potentially being a target for future treatment or prevention of the disease.

\section{References}

1 Schwartz MW \& Porte D Jr. Diabetes, obesity, and the brain. Science $2005307375-379$.

2 Porte D, Jr \& Kahn SE. beta-cell dysfunction and failure in type 2 diabetes: potential mechanisms. Diabetes 200150 (Suppl 1) S160-S163.
3 Petersen KF, Dufour S, Befroy D, Garcia R \& Shulman GI. Impaired mitochondrial activity in the insulin-resistant offspring of patients with type 2 diabetes. New England Journal of Medicine 2004350 664-671.

4 Malecki MT. Genetics of type 2 diabetes mellitus. Diabetes Research and Clinical Practice 200568 (Suppl 1) S10-S21.

5 Gunton JE, Kulkarni RN, Yim S, Okada T, Hawthorne WJ, Tseng YH, Roberson RS, Ricordi C, O'Connell PJ, Gonzalez FJ \& Kahn CR. Loss of ARNT/HIF1beta mediates altered gene expression and pancreatic-islet dysfunction in human type 2 diabetes. Cell 2005 122 337-349.

Received 15 February 2006

Accepted 23 February 2006 